Article

\title{
Antibiotic Resistance Genes in Antibiotic-Free Chicken Farms
}

\author{
Yuhong Liu ${ }^{1,2} \mathbb{D}$, Michael Dyall-Smith ${ }^{1} \mathbb{D}$, Marc Marenda ${ }^{1}$, Hang-Wei Hu ${ }^{3}$, \\ Glenn Browning ${ }^{1,2}$ and Helen Billman-Jacobe ${ }^{1,2, *}$ \\ 1 Asia-Pacific Centre for Animal Health, Department of Veterinary Biosciences, Faculty of Veterinary and \\ Agricultural Sciences, Melbourne Veterinary School, The University of Melbourne, Parkville, VIC 3010, \\ Australia; yuhongl@student.unimelb.edu.au (Y.L.); mike.dyallsmith@gmail.com (M.D.-S.); \\ mmarenda@unimelb.edu.au (M.M.); glenfb@unimelb.edu.au (G.B.) \\ 2 National Centre for Antimicrobial Stewardship, The Peter Doherty Institute, Elizabeth St Melbourne, \\ VIC 3000, Australia \\ 3 School of Agriculture and Food, Faculty of Veterinary and Agricultural Sciences, The University of \\ Melbourne, Parkville, VIC 3010, Australia; hang-wei.hu@unimelb.edu.au \\ * Correspondence: hbj@unimelb.edu.au
}

Received: 30 January 2020; Accepted: 10 March 2020; Published: 13 March 2020

\begin{abstract}
Rising concern about the use of antibiotics in food production has resulted in many studies on the occurrence of antibiotic resistance genes (ARGs) in animal-associated bacterial communities. There are few baseline data on the abundance of ARGs on farms where chickens are intensively raised with little or no use of antibiotics. This study used a high-throughput quantitative PCR array to survey two antibiotic-free chicken farms for the occurrence of ARGs and mobile genetic elements known to enhance the spread of ARGs. No antibiotics had been used on the study farms for five years prior to this study. The results provide a baseline for the occurrence of resistance genes in the chicken production system without direct selective pressure.
\end{abstract}

Keywords: poultry; chicken; manure; microbiota; resistome

\section{Introduction}

Antibiotic usage in food animals raises concerns over the potential emergence and spread of resistant bacteria [1,2]. To limit the negative impacts, many countries have restricted or banned the use of specific antibiotics in food animals, especially those antibiotics used for nontherapeutic purposes or that are of high importance for human use [2]. In Australia, fluoroquinolones have never been approved for use in food animals, and the use of third generation cephalosporins is restricted [3]. In poultry, chlortetracycline is registered for the treatment of egg-producing chickens (layers), and several antibiotics, including amoxycillin, neomycin, lincomycin, spectinomycin and oxytetracycline, are registered for use in meat-producing chickens (broilers) [4]. Virginiamycin and zinc-bacitracin are allowed for the prevention and treatment of necrotic enteritis [4].

Previous studies of specific bacterial species isolated from Australian poultry have revealed antibiotic resistance. Some Escherichia coli isolates from chickens were resistant to tetracycline, ampicillin, trimethoprim-sufamethoxazole, streptomycin, spectinomycin, neomycin and florfenicol [5]. Enterococcus isolates have been reported with resistance to lincomycin, bacitracin, tetracycline and tylosin but no resistance to vancomycin or virginiamycin was reported [6]. Campylobacter isolates were found to be resistant to ampicillin, tetracycline and lincomycin, but no resistance to ciprofloxacin, gentamicin, erythromycin and tylosin was reported [4,7].

Sampling of individual animals is not always practical, especially when animals are raised on a large scale, such as caged chickens in commercial farms. In this case, environmental sampling is a 
cost-effective and efficient method to collect biomass representing a large population, and this has been used for monitoring the prevalence of pathogens in chicken flocks [8,9]. High-throughput quantitative PCR (HT-qPCR) and deep sequencing approaches have been used in a variety of human, animal and environmental samples to characterize the diversity of antibiotic resistance genes (ARGs) [10-14]. These methods are efficient and effective for the broad-spectrum detection and quantification of ARGs in complex samples.

The aim of this study was to assess the presence and diversity of ARGs and mobile genetic elements (MGEs) in poultry farms that had not used antibiotics for 5 years. The WaferGen HT-qPCR system was used to detect and quantify ARGs and MGEs in environmental samples from two chicken farms. The PCR primers targeted ARGs of the major antibiotic classes, and integrases and transposase genes. Caged chicken sheds from two types of farms were selected for investigation; the first was an egg production enterprise which housed caged layer chickens (Farm L), while the second was a broiler breeder farm (Farm B). The results should provide useful baseline information regarding ARG prevalence in the chicken production system without direct selective pressure.

\section{Results}

\subsection{ARGs and MGEs in the Caged Layer Shed in Farm L}

\subsubsection{Number of ARGs and MGEs}

The caged layer shed on farm L was sampled twice when the chickens were 23 and 33 weeks old. Five manure belt swabs were collected from the shed each time. The biomass from two manure belt swabs in the first sampling were combined (sample W23_2 and W23_3) in order to have sufficient biomass for DNA extraction. The ARGs and MGEs in the DNA extracts were quantified using the WaferGen HT-qPCR system and the detection limit was set at Ct 27. Most of the ARGs were below the limits of detection. The combined number of ARGs and MGEs detected in each sample were between 80 and 89, out of the 285 ARGs tested, and either 6 or 7 out of 10 MGEs tested (Figure 1). The proportions of the classes of ARGs did not change substantially between samples.

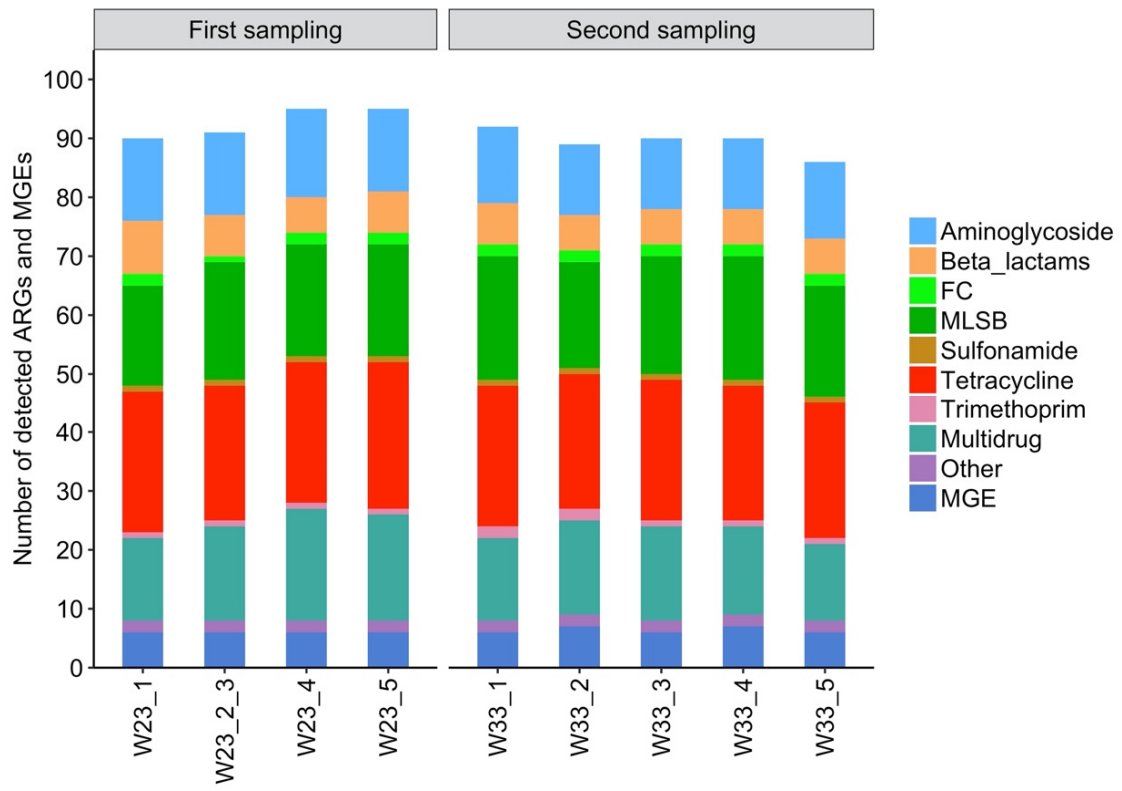

Figure 1. Number of detected antibiotic resistance genes (ARGs) and mobile genetic elements (MGEs) in each manure belt swab from the caged layer shed of each sampling visit on Farm $\mathrm{L}$. The sampling was performed when the chickens were 23 weeks (W23) and 33 weeks old (W33). Sample 2 and 3 for W23 were combined to provide a sufficient biomass for processing. FC, fluoroquinolone/florfenicol/chloramphenicol; MLSB, macrolide-lincosamide-streptogramin B; MGE, mobile genetic element. 


\subsubsection{Abundance of ARGs and MGEs}

The relative abundance of ARGs within their bacterial community was represented by their proportion relative to the $16 \mathrm{~S}$ rRNA gene for each individual sample (Figure 2). The $\mathrm{Ct}$ for the $16 \mathrm{~S} \mathrm{rRNA}$ gene ranged between 8 and 12 and, after normalisation, the lowest relative abundance of ARG or MGE genes ranged between $10^{-6}$ and $10^{-5}$. ARGs with relative abundances above $10^{-3}$ in all the nine manure belt swab samples were aminoglycoside resistance genes aad $\mathrm{A}$, aad $\mathrm{A} 1$, aad $\mathrm{A} 2$ and $\operatorname{str} \mathrm{B}$, sulfonamide resistance gene sul2 and tetracycline resistance genes tet $\mathrm{M}$, tet $\mathrm{K}$ and tet $\mathrm{X}$ (Table 1). The $c p h \mathrm{~A}$ gene was detected at high abundance $\left(\sim 10^{-1}\right)$ in one manure belt swab from the first sampling, but the gene was below the detection limit in the next sampling.

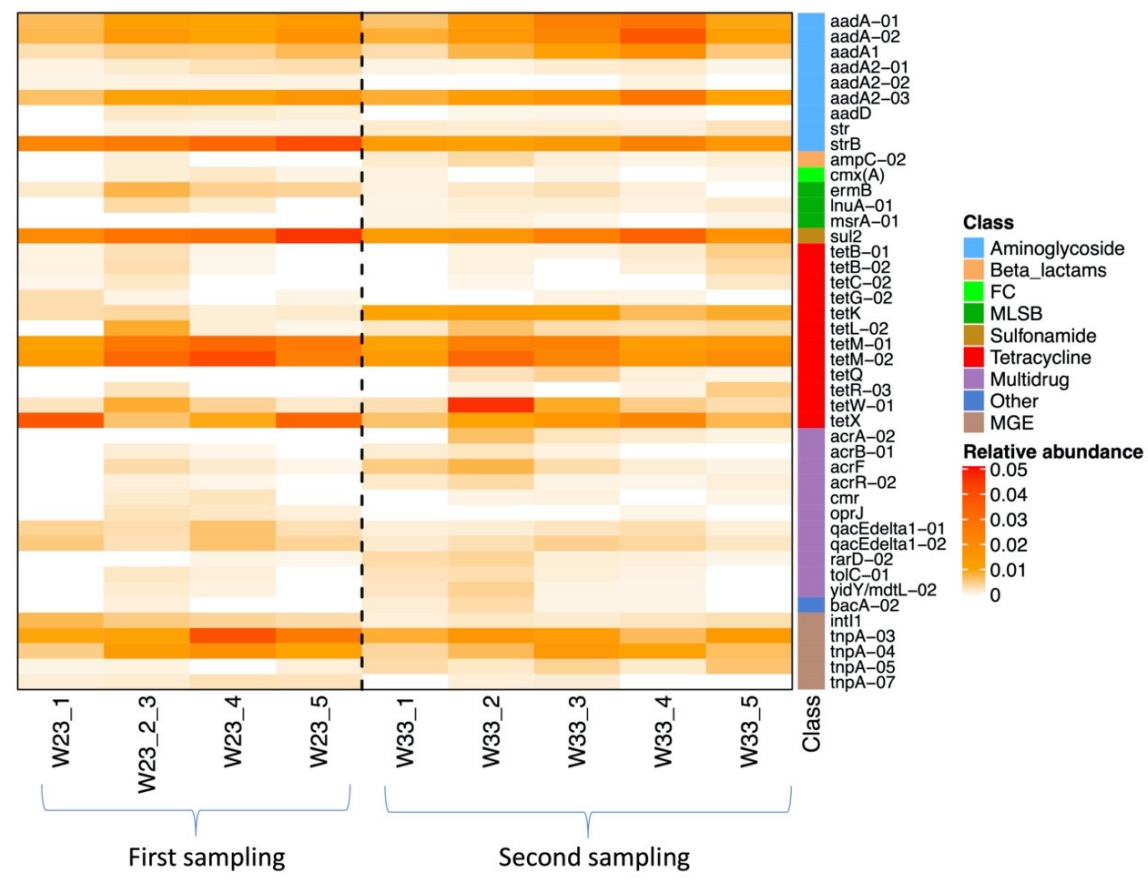

Figure 2. Heatmap of the relative abundance of ARGs and MGEs in each manure swab sample in Farm L. Only genes with a relative abundance above $10^{-3}$ in at least four samples are shown. FC, fluoroquinolone/florfenicol/chloramphenicol; MLSB, macrolide-lincosamide-streptogramin B; MGE, mobile genetic element.

Table 1. Most abundant ARGs in the layer Farm L.

\begin{tabular}{cccc}
\hline \multirow{2}{*}{ Gene } & \multicolumn{3}{c}{ Relative Abundance } \\
\cline { 2 - 4 } & Min & Max & Median \\
\hline aadA & $6.5 \times 10^{-3}$ & $2.9 \times 10^{-2}$ & $1.2 \times 10^{-2}$ \\
aadA1 & $3.4 \times 10^{-3}$ & $1.9 \times 10^{-2}$ & $6.0 \times 10^{-3}$ \\
aadA2 & $1.0 \times 10^{-3}$ & $3.7 \times 10^{-3}$ & $2.1 \times 10^{-3}$ \\
str $\mathrm{B}$ & $1.2 \times 10^{-2}$ & $4.0 \times 10^{-2}$ & $2.3 \times 10^{-2}$ \\
sul2 & $1.3 \times 10^{-2}$ & $4.5 \times 10^{-2}$ & $2.5 \times 10^{-2}$ \\
tetK & $1.9 \times 10^{-3}$ & $1.3 \times 10^{-2}$ & $7.5 \times 10^{-3}$ \\
tet $\mathrm{M}$ & $1.1 \times 10^{-2}$ & $3.2 \times 10^{-2}$ & $2.3 \times 10^{-2}$ \\
tet $\mathrm{W}$ & $2.4 \times 10^{-3}$ & $4.6 \times 10^{-2}$ & $4.9 \times 10^{-3}$ \\
tet $\mathrm{X}$ & $6.7 \times 10^{-3}$ & $3.7 \times 10^{-2}$ & $1.1 \times 10^{-2}$ \\
\hline
\end{tabular}

\subsubsection{Microbiota Analysis of Manure Belt swabs of Farm L}

A total of 316,232 reads of the four manure belt swabs from the first sampling passed the quality filter. The original read depth of all samples ranged between 68,312 and 86,951 . Reads of each sample 
were rarefied to 68,312 , which was sufficient for the accurate analysis of microbiota richness and evenness. The rarefied reads were partitioned into 450 ASVs and assigned with taxonomic information.

Proteobacteria was the most dominant phylum in sample W23_1 and W23_5, which accounted for $80 \%$ and $49 \%$ of the total reads, respectively (Figure 3a). In sample W23_2_3 and W23_4, the most abundant phylum was Firmicutes, which accounted for $37 \%$ and $45 \%$ of the total reads, respectively (Figure 3a). Actinobacteria was the next most abundant phylum in sample W23_2_3, W23_4 and W23_5, which accounted for $25 \%, 30 \%$ and $19 \%$ of the total reads, respectively (Figure 3a).

(a)
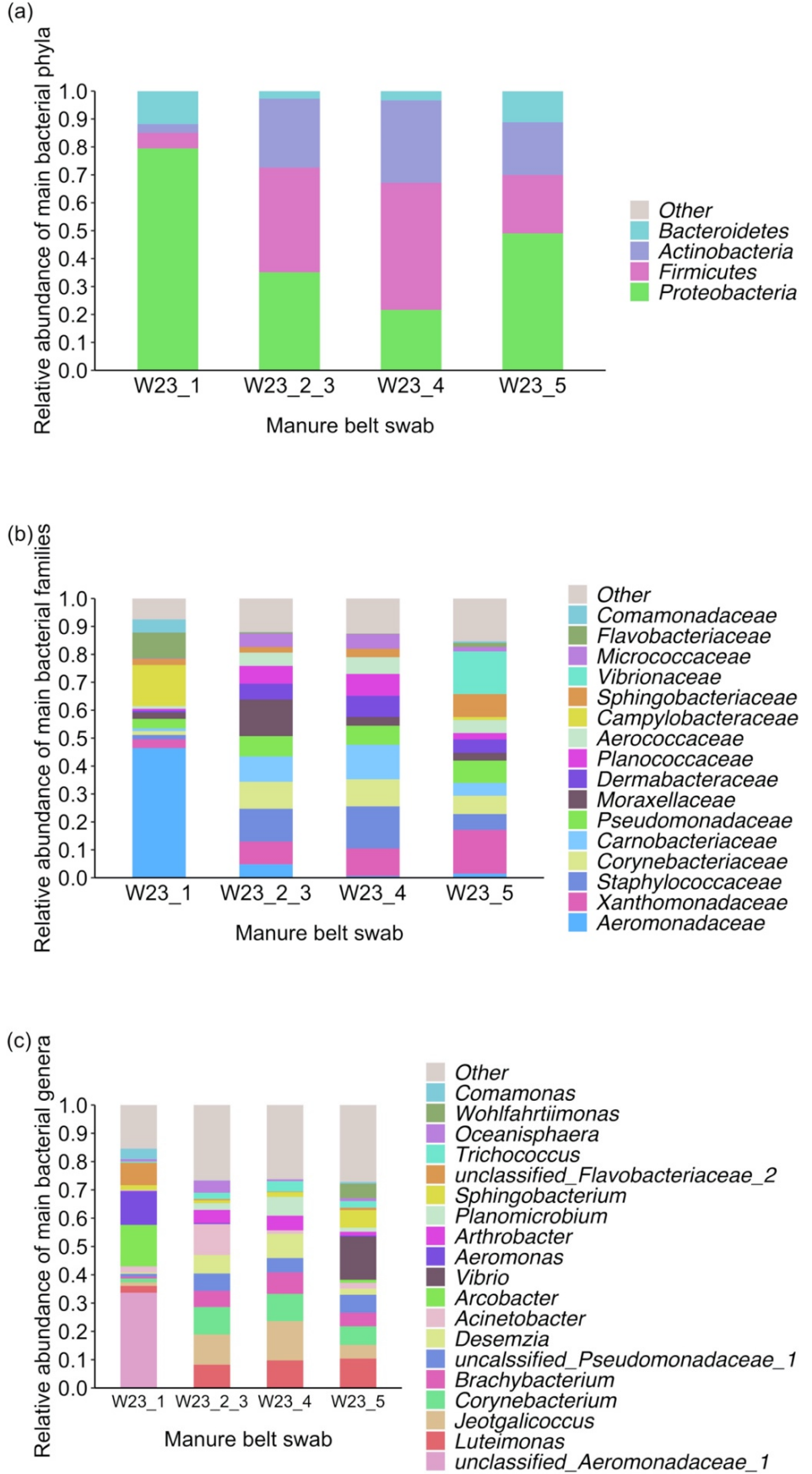

Figure 3. Relative abundance of dominant bacterial phyla (a), families (b) and genera (c) in the manure belt swabs of the first sampling in Farm L. Only taxa with relative abundance above 3\% in at least one sample are shown. Taxa below the cut off were assigned as "other". 
Proteobacteria in sample W23_1 was mainly represented by bacteria belonging to the Aeromonadaceae family and Arcobacter genus (Campylobacteraceae family), which accounted for $46 \%$ and $15 \%$ of the total reads, respectively (Figure 3c). In the other three samples, genus Luteimonas, Jeotgalicoccus, Corynebacterium and Brachybacterium were predominant in the microbiota, which together represented $27 \%$ to $41 \%$ of the total reads (Figure 3c). Moreover, sample W23_2_3 had a high level of Acinetobacter genus (11\%) and sample W23_5 had a high level of Vibrio genus (15\%) (Figure 3c).

\subsection{ARGs and MGEs in the Caged Broiler Breeder Sheds in Farm B}

\subsubsection{Number and Abundance of ARGs and MGEs}

The results of Farm L showed that the Ct of many of ARGs was above the cutoff of 27. It was not cost-effective to include all of the 295 ARGs and MGEs in further testing. Consequently, the HT-qPCR assay was reduced to 45 ARGs and four MGEs for samples from Farm B.

Three sheds of caged broiler breeder chickens were sampled on Farm B and 24 manure belt swabs were collected from each shed. Samples that failed to amplify the 16S rRNA gene were excluded in the analysis, leaving 22 swabs that were validated for sheds A and B, respectively, and 16 swabs in shed C.

Each shed was detected with 44 genes and the three sheds shared 42 genes. The relative abundance of genes detected in Farm B is shown in the heatmap (Figure 4). A total of 34 genes were detected in more than $80 \%$ samples (48 out of 60 ). The most abundant ARG was the aminoglycoside resistance gene str $\mathrm{B}$, with a median relative abundance of $1.3 \times 10^{-2}$. The next most abundant ARG was tetracycline resistance gene tet $\mathrm{L}$, with the median relative abundance of $1.2 \times 10^{-2}$, and the other two abundant tet genes were tet $\mathrm{M}$ and tetX. Other abundant genes were $s u l 2, \operatorname{erm} \mathrm{B}, \operatorname{aad} \mathrm{A}$ and $\operatorname{aad} \mathrm{A} 2$. In addition, the class I integron markers intI1 and qacE $\Delta$ were detected at high levels in the sheds, with median relative abundances of $1.8 \times 10^{-2}$ and $1.1 \times 10^{-2}$, respectively (Table 2). Relative abundances of these genes were further compared among the sheds using a pairwise Wilcoxon rank sum test. Three genes (tet X, aadA and aadA2) showed no significant differences in abundance between sheds. Shed A had significantly different abundances of gene tet $\mathrm{L}$, tet $\mathrm{M}, \operatorname{str} \mathrm{B}, \operatorname{sul} 2, \operatorname{erm} \mathrm{B}$, int $\mathrm{I} 1$, qac $\mathrm{E}$ compared to shed B and/or shed C ( $p<0.05)$. Sheds B and C had significantly different abundances of gene tet $\mathrm{L}$, $e r m \mathrm{~B}, \mathrm{i} n t \mathrm{I} 1$ and $q a c \mathrm{E} \Delta(p<0.05)$. The ARGs with high human clinical importance, such as the beta lactamase resistance genes blaSHV, blaCTX-M, cphA, the fluoroquinolone resistance gene $q n r \mathrm{~B}$ and the virginiamycin resistance gene vatE, detected at very low abundances $\left(\sim 10^{-6}\right.$ to $\left.10^{-5}\right)$ in the samples.

Table 2. Most abundant ARGs and MGEs in the broiler breeder Farm B.

\begin{tabular}{cccc}
\hline \multirow{2}{*}{ Gene } & \multicolumn{3}{c}{ Relative Abundance } \\
\cline { 2 - 4 } & Min & Max & Median \\
\hline aadA & $6.4 \times 10^{-4}$ & $6.7 \times 10^{-2}$ & $7.2 \times 10^{-3}$ \\
aadA2 & $5.0 \times 10^{-4}$ & $3.8 \times 10^{-2}$ & $5.6 \times 10^{-3}$ \\
strB & $7.0 \times 10^{-4}$ & $2.1 \times 10^{-1}$ & $1.3 \times 10^{-2}$ \\
erm $\mathrm{B}$ & $1.4 \times 10^{-3}$ & $3.0 \times 10^{-2}$ & $6.3 \times 10^{-3}$ \\
sul2 & $1.5 \times 10^{-4}$ & $3.4 \times 10^{-1}$ & $8.0 \times 10^{-3}$ \\
intl1 & $6.8 \times 10^{-4}$ & $7.9 \times 10^{-2}$ & $1.8 \times 10^{-2}$ \\
qacE $\Delta$ & $1.3 \times 10^{-3}$ & $5.4 \times 10^{-2}$ & $1.1 \times 10^{-2}$ \\
tet $\mathrm{L}$ & $1.0 \times 10^{-3}$ & $5.5 \times 10^{-2}$ & $1.2 \times 10^{-2}$ \\
tet $\mathrm{M}$ & $1.8 \times 10^{-3}$ & $3.0 \times 10^{-2}$ & $9.2 \times 10^{-3}$ \\
tet $\mathrm{X}$ & $2.2 \times 10^{-4}$ & $3.8 \times 10^{-2}$ & $7.7 \times 10^{-3}$ \\
\hline
\end{tabular}




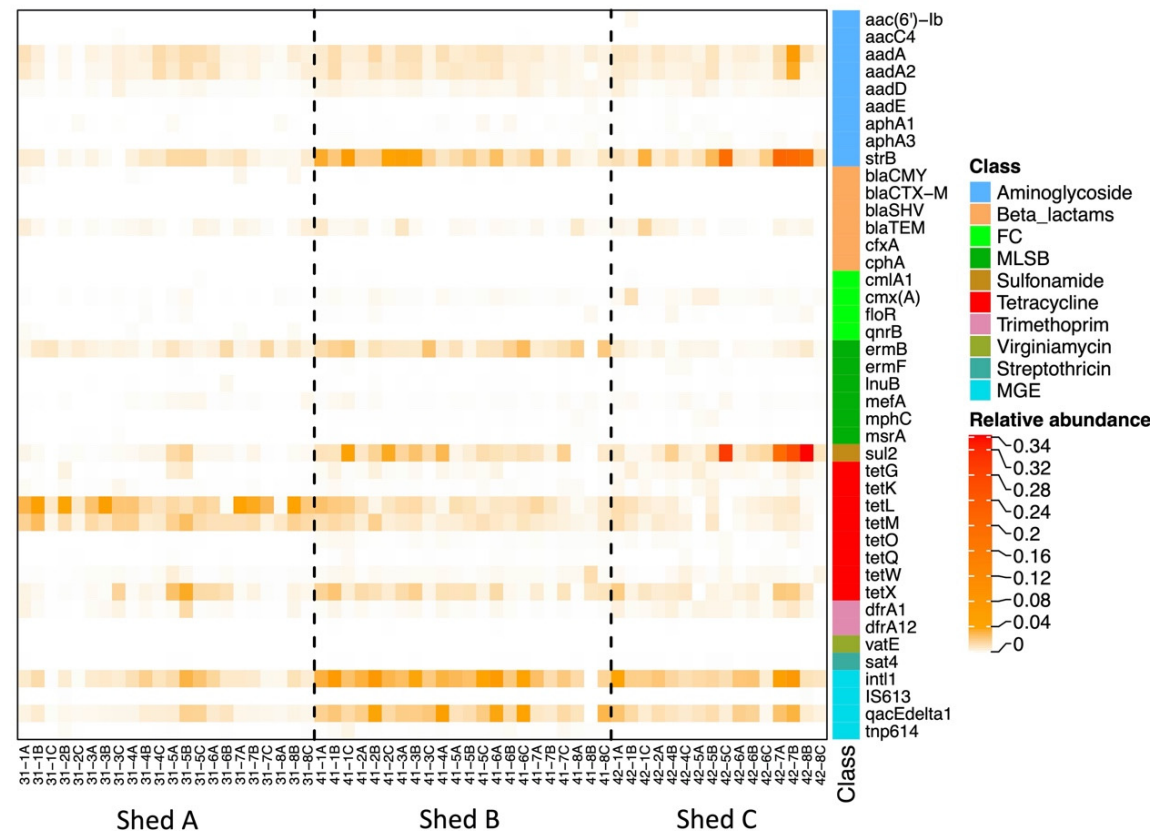

Figure 4. Heatmap of the relative abundance of ARGs and MGEs in all manure belt samples from three sheds in Farm B. FC, fluoroquinolone/florfenicol/chloramphenicol; MLSB, macrolide-lincosamidestreptogramin B; MGE, mobile genetic element.

2.2.2. Similarity of ARG and MGE Profiles between Sheds and Farms

NMDS analysis using Bray-Curtis distance derived from the relative abundance of ARGs and MGEs was used to explore sample clustering based on sheds in Farm B. The results are shown in Figure 5 and reveal a separation of shed A from sheds B and C $(R=0.39, p=0.001$, ANOSIM).

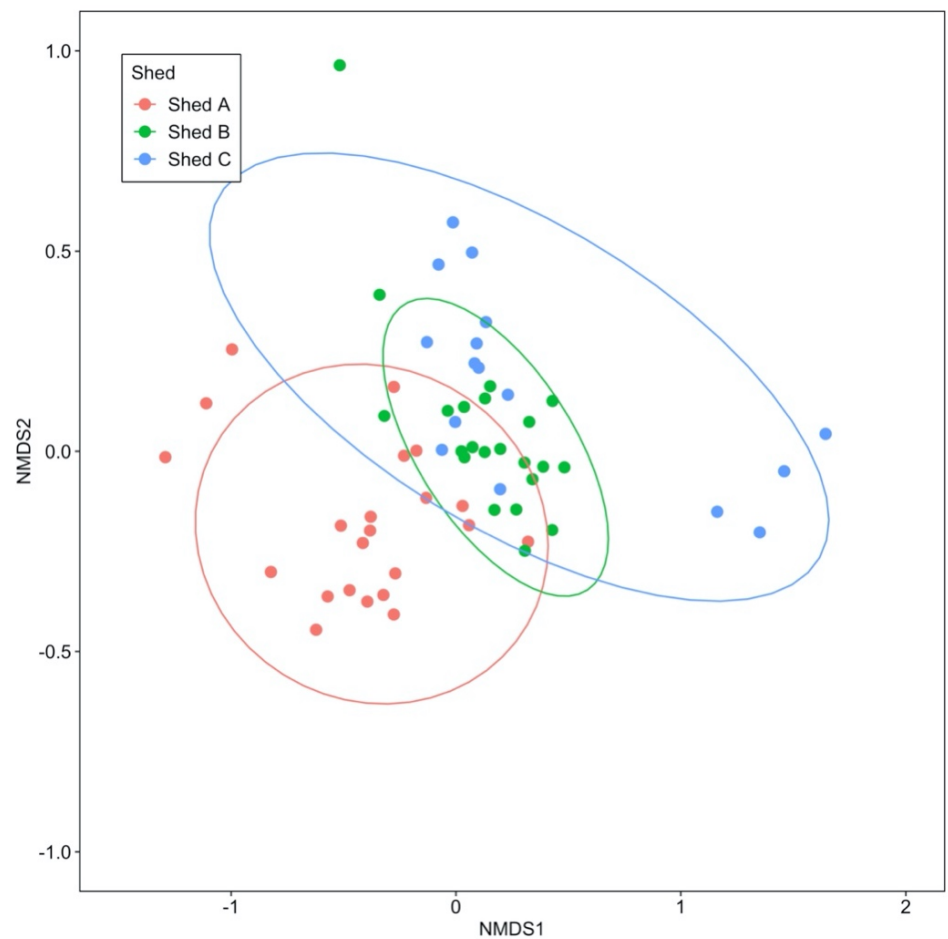

Figure 5. NMDS using Bray-Curtis distances to compare the similarity of ARG profiles of the manure belt swabs between the sheds in the broiler breeder Farm B. The ellipses indicate 95\% confidence region of each cluster. 
The ARG profile of manure belt swabs of Farm B was further compared to that of the layer Farm L. NMDS analysis was based on the relative abundance of 33 ARGs detected in both farms. No significant difference was found between the two farms ( $\mathrm{R}=0.17, p=0.08$, ANOSIM) (Figure 6).

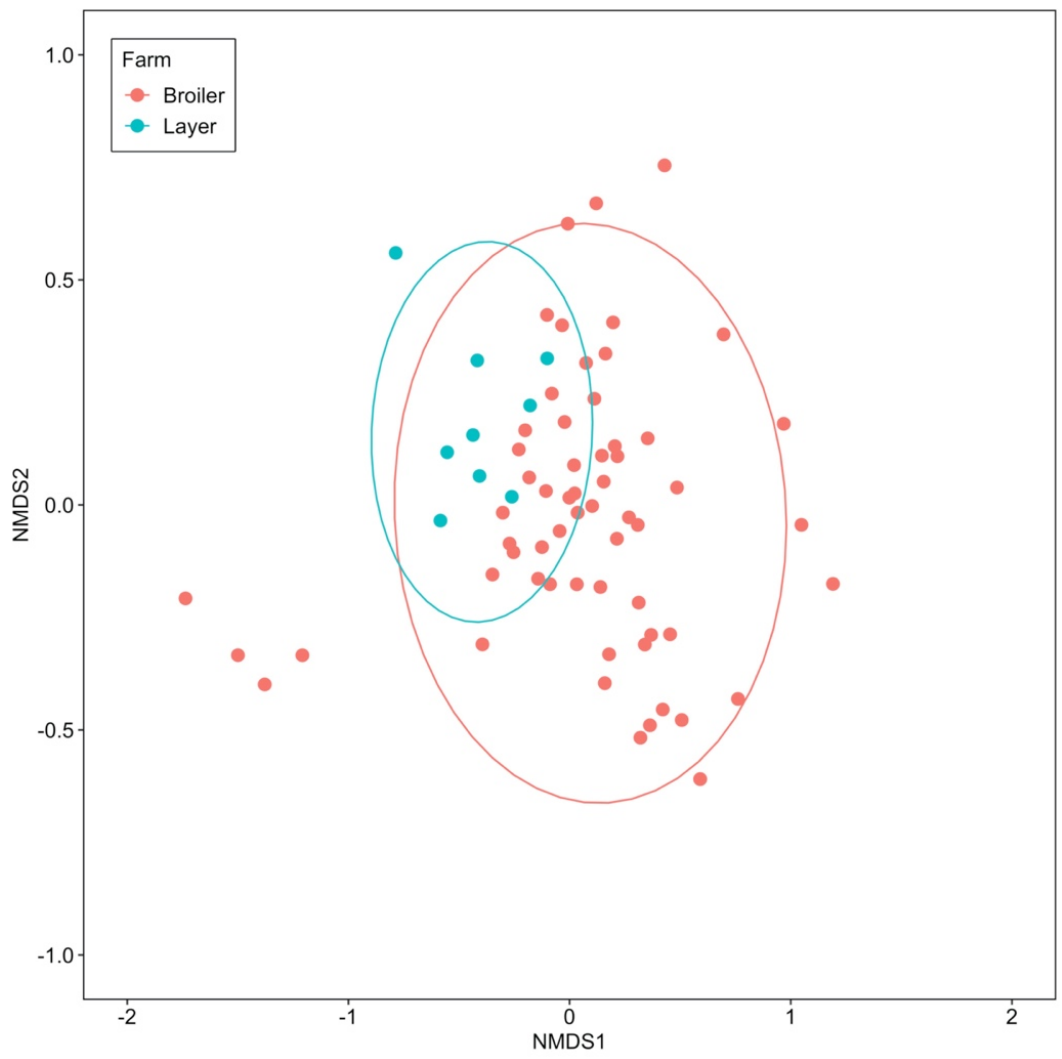

Figure 6. NMDS using Bray-Curtis distances to compare the similarity of the manure belt swab ARG profiles between layer Farm L and broiler breeder Farm B. The analysis was based on the relative abundance of 33 ARGs detected in both farms. The ellipses indicate $95 \%$ confidence region of each cluster.

\section{Discussion}

This work explored the ARG profile in two antibiotic-free farms, a layer farm and a broiler breeder farm. Manure belt swabs were used for sampling as this was easy to perform in a large chicken shed, and the biomass collected on the swabs represented a large number of birds. The manure belt swabs collected in layer Farm L showed a high abundance of tet $\mathrm{M}$, sul2 and $\operatorname{str} \mathrm{B}$, which agreed with the results of previous studies that examined the resistome of intensively reared chickens $[15,16]$. Indeed, tetracycline resistance genes, particularly, tet $\mathrm{Q}$, tet $\mathrm{W}$ and tet $\mathrm{M}$, have been found to be ubiquitous in faecal specimens from human and animals [11,14,17].

The sul2 gene is plasmid borne, and has been found in plasmids from different incompatibility groups and often linked to streptomycin resistance genes strA and strB [18-20]. A recent study reported that the sul2-strA-strB cluster could be found in ice core samples from Antarctica that were over 1000 years old, suggesting that the formation and dissemination of this ARG cluster can happen without human interventions involving antibiotic use [21]. In the current study, no antibiotics had been used on this farm for more than 5 years, so the prevalence of these ARGs in this layer farm was not likely driven by antibiotic selective pressure and is more likely a reflection of their baseline abundances in the farming environment.

Analysis of the microbiota profile of the manure belt swabs showed a dominance of family Aeromonadaceae and genus Luteimonas, Jeotgalicoccus, Corynebacterium and Brachybacterium in the samples. 
The Corynebacterium genus was found abundant in chicken duodenum, jejunum, ileum, and colon [22]. However, other genera, such as Lactobacillus, Enterococcus, Bacteriodes and Ruminococcus, reported as abundant in the chicken gastrointestinal tract [22,23], were rarely detected in our results. The divergency might be explained by the differences between samples. Previous studies usually collected fresh chicken faeces or gut contents, while, in our study, faecal material collected from the manure belt would have been exposed and the faecal microbiota could be impacted by environmental factors, such as oxygen, temperature and moisture. Indeed, Luteimonas, Corynebacterium and Brachybacterium were usually detected in chicken litter and Corynebacterium was one of the major genera in the litter microbiota [24,25].

The results of the Farm L study showed that many of the qPCRs were negative, which was consistent with the antibiotic-free policy of this farm. The results from the study of Farm $\mathrm{L}$ informed the experimental design of the study of Farm B, which also did not use antibiotics. A reduced set of HT-qPCR primers was selected for use in the Farm B study, which allowed more samples to be analysed while still maintaining broad coverage of the most frequent ARGs and MGEs present.

Farm B samples had abundant tetracycline resistance genes in most samples. This is consistent with findings on Farm L and other studies quantifying ARGs in faecal samples from poultry [26,27], swine [14,28] and humans [11,17]. These tet genes are known to be present in a wide range of bacterial species [29], some of which are members of the dominant flora of the normal chicken gastrointestinal tract and chicken litter, such as Clostridium, Lactobacillus, Bacteroides and Corynebacterium [23]. Metagenomic studies have shown that the ribosome protection type tet genes contribute about $30 \%$ to the total ARG abundance in the chicken cecum [30], and many tet genes are often associated with mobile elements in diverse species [31-35]. The macrolide resistance gene erm $\mathrm{B}$ was also found to be abundant in samples across all broiler sheds. Similar to the tet genes, ermB was also detected in a wide range of bacterial species [29] and associated with conjugative transposons [36-38], which may explain the wide dissemination of the gene in the environment.

Moreover, the ARG profile of the manure belt swabs from Farm B was similar to that from the Farm L. The comparison included ARGs that were detected at high levels in both farms, such as tetM, tet $\mathrm{X}, \mathrm{str} \mathrm{B}$ and sul2. As both farms were antibiotic-free for at least 5 years prior to sampling, the result indicates that those ARGs were ubiquitous in poultry manure and their presence was not necessarily related to human antibiotic usage.

In conclusion, this study showed that HT-qPCR can be used for surveying chicken farm environments, and that manure belt sampling is both convenient and useful as long as the physical design of the housing permits access to the belt. The ARG profiles for the two farms were similar. The ARGs with higher abundances, particularly tet $\mathrm{M}$, strB and sul2, were likely due to their carriage by bacterial species naturally present in the chicken faecal microbiota, or because these genes have been already spread widely in the environment and were not the result of selection due to antibiotic use.

\section{Materials and Methods}

\subsection{Study Farms and Chickens}

In the layer Farm L, birds in the caged shed were kept in cages with six birds per cage. The study shed housed around 65,000 birds in five frames six tiers high. Manure accumulated on a conveyor belt beneath each tier of cages and was removed weekly.

In the broiler breeder Farm B, the birds were housed in frames three to four tiers high. Each shed contained eight frames which housed around 24,000 birds in total. Three sheds on the farm were sampled. Birds in shed B and C were originally from the same cohort of chicks and birds in shed A were from a different cohort. 


\subsection{Sampling}

The caged layer shed in Farm L was sampled twice when the birds were 23 and 33 weeks old, respectively. One manure belt per frame was sampled and there were five frames in total. In Farm B, three manure belts of each frame were sampled, and 24 swabs were collected from each shed.

The manure belts were sampled according to the method described in [9]. Manure belt swabs were collected by wiping the edge of one end of the manure belt, using sterile $10 \times 10 \mathrm{~cm}$ cotton gauze swabs (ZebraVet, Australia) premoistened with buffered peptone water. Swabs were stored in sterile plastic bags and transported to the laboratory at ambient temperature. Samples from Farm L were transported to the laboratory on the same day of collection, and samples from Farm B were transported to the laboratory the next morning within $24 \mathrm{~h}$ of collection. Upon receipt, the biomass was collected from the swabs and frozen at $-80^{\circ} \mathrm{C}$ until DNA extraction.

\subsection{DNA Extraction}

The swabs were rinsed in $50 \mathrm{ml}$ peptone and the biomass was collected by centrifugation at $2885 \times g$ for $30 \mathrm{~min}$ at $4{ }^{\circ} \mathrm{C}$ (Allegra X-12R centrifuge, Beckman Coulter, USA). The pellet was stored in one $2 \mathrm{ml}$ microcentrifuge tube and stored at $-80^{\circ} \mathrm{C}$ until DNA extraction.

DNA was extracted using the DNeasy PowerSoil Kit (Qiagen, Carlsbad, CA, USA) according to the manufacturer's instructions, except that the biomass mixed with buffer $\mathrm{C} 1$ was processed with a FastPrep homogeniser (Bio101, USA) at $5.5 \mathrm{~m} / \mathrm{s}$ for $30 \mathrm{~s}$. DNA quality and quantity were checked by Nanodrop (Thermo Fisher Scientific, USA) and Qubit (Thermo Fisher Scientific, USA), respectively. DNA was store at $-20^{\circ} \mathrm{C}$ until analysis.

\subsection{HT-qPCR Array for Detection and Quantification of ARGs and MGEs}

ARGs and MGEs were detected by the WaferGen SmartChip Real-time PCR system (WaferGen Inc. USA).

For Farm L, the array contained 296 validated primers targeting 285 ARGs, 10 mobile genetic elements (MGEs), and one 16S rRNA gene (Table S1) [13,14]. The assay includes genes from all major classes of ARGs, including aminoglycoside, beta lactamase, fluoroquinolone/florfenicol/ chloramphenicol (FC), macrolide-lincosamide-streptogramin B (MLSB), sulfonamide, trimethoprim, tetracycline, vancomycin, multidrug resistance and other resistance genes. For Farm B, 45 primers were used to amplify ARGs, four primer pairs were used to amplify MGEs and one primer pair was specific to the bacterial 16S rRNA gene (Table S2). The qPCR conditions have been described previously [39]. The cycle threshold (Ct) cut-off was 27 [14]. The abundance of each ARG was normalised to the 16S rRNA gene in each sample using the equation Relative abundance $=\frac{\mathrm{E}(16 \mathrm{~S})^{\mathrm{Ct}(16 \mathrm{~S})}}{\mathrm{E}(\mathrm{ARG})^{\mathrm{Ct}(\mathrm{ARG})}}$, where $\mathrm{E}(16 \mathrm{~S})$ is the efficiency of the $16 \mathrm{~S}$ rRNA gene, E(ARG) is the efficiency of each ARG or MGE, and Ct is the threshold cycle $[40,41]$.

\subsection{Bacterial 16S rRNA Sequencing and Bioinformatic Analyses}

Bacterial communities in the manure belt swabs (Farm L) of the first sampling were characterised by sequencing the V3-V4 region of the $16 \mathrm{~S}$ rRNA gene using the Illumina MiSeq platform. Primers were as follows: forward primer (342F): 5'-CCTAYGGGRBGCASCAG-3', reverse primer (806R): 5'-GGACTACNNGGGTATCTAA-3' [42,43]. Sequences were processed through the QIIME2 pipeline (Version qiime2-2018.11) [44]. De-multiplexed reads were trimmed to 250bp, de-noised, paired and grouped into amplicon sequence variants (ASVs) by DADA2 [45]. ASVs only present in a single sample or classified as non-bacteria were removed. Taxonomy was assigned using a pre-trained Naïve Bayes classifier with the Greengenes database (2013 August release) [46,47]. For fair comparison, sequence depth was equalised by randomly subsampling the same number of reads of each sample from the original dataset. The minimum number of reads that would not affect coverage or discard any samples was used. 


\subsection{Statistical Analysis}

A heatmap of the relative abundance of each gene in each sample of Farm L and Farm B was generated using the ComplexHeatmap R package [48].

Differences in the relative abundance of ARGs between sheds in Farm B were tested by pairwise Wilcoxon rank sum test with P value adjusted by the Benjamini-Hochberg correction method [49] using the basic stats $\mathrm{R}$ package. A $\mathrm{P}$ value less than 0.05 was considered as a significant difference.

The similarity of ARG profiles of the manure belt swabs between sheds in Farm B was compared using the NMDS method with Bray-Curtis distance matrix based on the relative abundance of ARGs and MGEs. Similarity between sheds was tested by analysis of similarity (ANOSIM) using the 'anosim' function in the vegan package of R. NMDS analysis results were plotted using the ggplot2 R package with ellipses indicating the $95 \%$ confidence region of each cluster.

The similarity of ARG profiles of manure belt swabs between Farm L and Farm B was tested based on the relative abundance of ARGs tested in both farms, using the NMDS and ANOSIM methods described above.

Supplementary Materials: The following are available online at http://www.mdpi.com/2079-6382/9/3/120/s1, Table S1: qPCR primers for ARGs and MGEs in Farm L, Table S2: qPCR primers for ARGs and MGEs in Farm B.

Author Contributions: Conceptualization, Y.L., G.B., M.D.-S., M.M., H.B.-J.; methodology, Y.L., H.-W.H. and H.B.-J.; writing - original draft preparation, Y.L.; writing-review and editing, H.B.-J., M.D.-S., M.M.; G.B., supervision, H.B.-J., M.D.-S., M.M.; funding acquisition, H.B.-J. and G.B. All authors have read and agreed to the published version of the manuscript.

Funding: This research was funded by the National Health and Medical Research Council through the Centres of Research Excellence Programme, Grant no. 1079625.

Acknowledgments: YL received a Melbourne Research Scholarship from the University of Melbourne. The authors wish to thank Helen Crabb for assistance with sample collection.

Conflicts of Interest: The authors declare no conflict of interest.

\section{References}

1. Landers, T.F.; Cohen, B.; Wittum, T.E.; Larson, E.L. A review of antibiotic use in food animals: Perspective, policy, and potential. Public Health Rep. 2012, 127, 4-22. [CrossRef] [PubMed]

2. Marshall, B.M.; Levy, S.B. Food animals and antimicrobials: Impacts on human health. Clin. Microbiol. Rev. 2011, 24, 718-733. [CrossRef]

3. APVMA. Antibiotic Resistance in Animals. Available online: https://apvma.gov.au/our-science/14596/ publications/27326 (accessed on 27 June 2018).

4. Obeng, A.; Rickard, H.; Sexton, M.; Pang, Y.; Peng, H.; Barton, M. Antimicrobial susceptibilities and resistance genes in Campylobacter strains isolated from poultry and pigs in Australia. J. Appl. Microbiol. 2012, 113, 294-307. [CrossRef] [PubMed]

5. Obeng, A.S.; Rickard, H.; Ndi, O.; Sexton, M.; Barton, M. Antibiotic resistance, phylogenetic grouping and virulence potential of Escherichia coli isolated from the faeces of intensively farmed and free range poultry. Vet. Microbiol. 2012, 154, 305-315. [CrossRef] [PubMed]

6. Obeng, A.S.; Rickard, H.; Ndi, O.; Sexton, M.; Barton, M. Comparison of antimicrobial resistance patterns in enterococci from intensive and free range chickens in Australia. Avian Pathol. 2013, 42, 45-54. [CrossRef]

7. Miflin, J.K.; Templeton, J.M.; Blackall, P. Antibiotic resistance in Campylobacter jejuni and Campylobacter coli isolated from poultry in the South-East Queensland region. J. Antimicrob. Chemother. 2007, 59, 775-778. [CrossRef]

8. Arnold, M.; Carrique-Mas, J.; Davies, R. Sensitivity of environmental sampling methods for detecting Salmonella Enteritidis in commercial laying flocks relative to the within-flock prevalence. Epidemiol. Infect. 2010, 138, 330-339. [CrossRef]

9. Crabb, H.K.; Allen, J.L.; Devlin, J.M.; Wilks, C.R.; Gilkerson, J.R. Spatial distribution of Salmonella enterica in poultry shed environments observed by intensive longitudinal environmental sampling. Appl. Environ. Microbiol. 2019, 19, e00333-19. [CrossRef] 
10. Johnson, T.A.; Stedtfeld, R.D.; Wang, Q.; Cole, J.R.; Hashsham, S.A.; Looft, T.; Zhu, Y.G.; Tiedje, J.M. Clusters of antibiotic resistance genes enriched together stay together in swine agriculture. mBio 2016, 7, e02214-e02215. [CrossRef]

11. Li, B.; Yang, Y.; Ma, L.; Ju, F.; Guo, F.; Tiedje, J.M.; Zhang, T. Metagenomic and network analysis reveal wide distribution and co-occurrence of environmental antibiotic resistance genes. ISME J. 2015, 9, 2490-2502. [CrossRef]

12. Lin, W.; Zhang, M.; Zhang, S.; Yu, X. Can chlorination co-select antibiotic-resistance genes? Chemosphere 2016, 156, 412-419. [CrossRef] [PubMed]

13. Looft, T.; Johnson, T.A.; Allen, H.K.; Bayles, D.O.; Alt, D.P.; Stedtfeld, R.D.; Sul, W.J.; Stedtfeld, T.M.; Chai, B.; Cole, J.R. In-feed antibiotic effects on the swine intestinal microbiome. Proc. Natl. Acad. Sci. USA 2012, 109, 1691-1696. [CrossRef] [PubMed]

14. Zhu, Y.G.; Johnson, T.A.; Su, J.Q.; Qiao, M.; Guo, G.X.; Stedtfeld, R.D.; Hashsham, S.A.; Tiedje, J.M. Diverse and abundant antibiotic resistance genes in Chinese swine farms. Proc. Natl. Acad. Sci. USA 2013, 110, 3435-3440. [CrossRef] [PubMed]

15. Guo, X.; Stedtfeld, R.D.; Hedman, H.; Eisenberg, J.N.; Trueba, G.; Yin, D.; Tiedje, J.M.; Zhang, L. Antibiotic resistome associated with small-scale poultry production in rural Ecuador. Environ. Sci. Technol. 2018, 52, 8165-8172. [CrossRef]

16. He, L.Y.; Liu, Y.S.; Su, H.C.; Zhao, J.L.; Liu, S.S.; Chen, J.; Liu, W.R.; Ying, G.G. Dissemination of antibiotic resistance genes in representative broiler feedlots environments: Identification of indicator ARGs and correlations with environmental variables. Environ. Sci. Technol. 2014, 48, 13120-13129. [CrossRef]

17. Seville, L.A.; Patterson, A.J.; Scott, K.P.; Mullany, P.; Quail, M.A.; Parkhill, J.; Ready, D.; Wilson, M.; Spratt, D.; Roberts, A.P. Distribution of tetracycline and erythromycin resistance genes among human oral and fecal metagenomic DNA. Microb. Drug Resist. 2009, 15, 159-166. [CrossRef]

18. Bean, D.C.; Livermore, D.M.; Hall, L.M. Plasmids imparting sulfonamide resistance in Escherichia coli: Implications for persistence. Antimicrob. Agents Chemother. 2009, 53, 1088-1093. [CrossRef]

19. Vinué, L.; Sáenz, Y.; Rojo-Bezares, B.; Olarte, I.; Undabeitia, E.; Somalo, S.; Zarazaga, M.; Torres, C. Genetic environment of sul genes and characterisation of integrons in Escherichia coli isolates of blood origin in a Spanish hospital. Int. J. Antimicrob. Agents 2010, 35, 492-496. [CrossRef]

20. Yau, S.; Liu, X.; Djordjevic, S.P.; Hall, R.M. RSF1010-like plasmids in Australian Salmonella enterica serovar Typhimurium and origin of their sul2-strA-strB antibiotic resistance gene cluster. Microb. Drug Resist. 2010, 16, 249-252. [CrossRef]

21. Okubo, T.; Ae, R.; Noda, J.; Iizuka, Y.; Usui, M.; Tamura, Y. Detection of the sul2-strA-strB gene cluster in an ice core from Dome Fuji Station, East Antarctica. J. Glob. Antimicrob Resist. 2019, 17, 72-78. [CrossRef]

22. Xiao, Y.; Xiang, Y.; Zhou, W.; Chen, J.; Li, K.; Yang, H. Microbial community mapping in intestinal tract of broiler chicken. Poult. Sci. 2017, 96, 1387-1393. [CrossRef] [PubMed]

23. Wei, S.; Morrison, M.; Yu, Z. Bacterial census of poultry intestinal microbiome. Poult. Sci. 2013, 92, 671-683. [CrossRef] [PubMed]

24. Lu, J.; Sanchez, S.; Hofacre, C.; Maurer, J.J.; Harmon, B.G.; Lee, M.D. Evaluation of broiler litter with reference to the microbial composition as assessed by using $16 \mathrm{~S}$ rRNA and functional gene markers. Appl. Environ. Microbiol. 2003, 69, 901-908. [CrossRef] [PubMed]

25. Wang, L.; Lilburn, M.; Yu, Z. Intestinal microbiota of broiler chickens as affected by litter management regimens. Front. Microbiol. 2016, 7, 1-12. [CrossRef] [PubMed]

26. Cheng, W.; Chen, H.; Su, C.; Yan, S. Abundance and persistence of antibiotic resistance genes in livestock farms: A comprehensive investigation in eastern China. Environ. Int. 2013, 61, 1-7. [CrossRef] [PubMed]

27. Ji, X.; Shen, Q.; Liu, F.; Ma, J.; Xu, G.; Wang, Y.; Wu, M. Antibiotic resistance gene abundances associated with antibiotics and heavy metals in animal manures and agricultural soils adjacent to feedlots in Shanghai; China. J. Hazard. Mater. 2012, 235-236, 178-185. [CrossRef] [PubMed]

28. Wang, R.; Chen, M.; Feng, F.; Zhang, J.; Sui, Q.; Tong, J.; Wei, Y.; Wei, D. Effects of chlortetracycline and copper on tetracyclines and copper resistance genes and microbial community during swine manure anaerobic digestion. Bioresour. Technol. 2017, 238, 57-69. [CrossRef]

29. Roberts, M.C.; Schwarz, S.; Aarts, H.J. Erratum: Acquired antibiotic resistance genes: An overview. Front. Microbiol. 2012, 3, 1-17. [CrossRef] 
30. Qu, A.; Brulc, J.M.; Wilson, M.K.; Law, B.F.; Theoret, J.R.; Joens, L.A.; Konkel, M.E.; Angly, F.; Dinsdale, E.A.; Edwards, R.A. Comparative metagenomics reveals host specific metavirulomes and horizontal gene transfer elements in the chicken cecum microbiome. PLOS ONE 2008, 3, e2945. [CrossRef]

31. Agersø, Y.; Jensen, L.B.; Givskov, M.; Roberts, M.C. The identification of a tetracycline resistance gene tet(M), on a Tn 916-like transposon, in the Bacillus cereus group. FEMS Microbiol. Lett. 2002, 214, 251-256. [CrossRef]

32. Agersø, Y.; Pedersen, A.G.; Aarestrup, F.M. Identification of Tn5397-like and Tn916-like transposons and diversity of the tetracycline resistance gene tet $(\mathrm{M})$ in enterococci from humans, pigs and poultry. J. Antimicrob. Chemother. 2006, 57, 832-839. [CrossRef] [PubMed]

33. Chopra, I.; Roberts, M. Tetracycline antibiotics: Mode of action, applications, molecular biology, and epidemiology of bacterial resistance. Microbiol. Mol. Biol. Rev. 2001, 65, 232-260. [CrossRef]

34. De Leener, E.; Martel, A.; Decostere, A.; Haesebrouck, F. Distribution of the erm(B) gene, tetracycline resistance genes, and Tn1545-like transposons in macrolide-and lincosamide-resistant enterococci from pigs and humans. Microb. Drug Resist. 2004, 10, 341-345. [CrossRef]

35. De Vries, L.E.; Christensen, H.; Skov, R.L.; Aarestrup, F.M.; Agersø, Y. Diversity of the tetracycline resistance gene tet(M) and identification of Tn 916-and Tn 5801-like (Tn 6014) transposons in Staphylococcus aureus from humans and animals. J. Antimicrob. Chemother. 2009, 64, 490-500. [CrossRef] [PubMed]

36. Cochetti, I.; Tili, E.; Vecchi, M.; Manzin, A.; Mingoia, M.; Varaldo, P.E.; Montanari, M.P. New Tn 916-related elements causing erm(B)-mediated erythromycin resistance in tetracycline-susceptible pneumococci. J. Antimicrob. Chemother. 2007, 60, 127-131. [CrossRef] [PubMed]

37. Gupta, A.; Vlamakis, H.; Shoemaker, N.; Salyers, A.A. A new Bacteroides conjugative transposon that carries an ermB gene. Appl. Environ. Microbiol. 2003, 69, 6455-6463. [CrossRef]

38. Okitsu, N.; Kaieda, S.; Yano, H.; Nakano, R.; Hosaka, Y.; Okamoto, R.; Kobayashi, T.; Inoue, M. Characterization of ermB gene transposition by Tn1545 and Tn917 in macrolide-resistant Streptococcus pneumoniae isolates. J. Clin. Microbiol. 2005, 43, 168-173. [CrossRef]

39. Wang, F.H.; Qiao, M.; Su, J.Q.; Chen, Z.; Zhou, X.; Zhu, Y.G. High throughput profiling of antibiotic resistance genes in urban park soils with reclaimed water irrigation. Environ. Sci. Technol. 2014, 48, 9079-9085. [CrossRef]

40. Muller, P.Y.; Janovjak, H.; Miserez, A.R.; Dobbie, Z. Erratum. BioTechniques 2002, 33, 514.

41. Muller, P.Y.; Janovjak, H.; Miserez, A.R.; Dobbie, Z. Processing of gene expression data generated by quantitative real-time RT-PCR. BioTechniques 2002, 32, 1372-1379.

42. Thijs, S.; Op De Beeck, M.; Beckers, B.; Truyens, S.; Stevens, V.; Van Hamme, J.D.; Weyens, N.; Vangronsveld, J. Comparative evaluation of four bacteria-specific primer pairs for $16 \mathrm{~S}$ rRNA gene surveys. Front. Microbiol. 2017, 8, 1-15. [CrossRef] [PubMed]

43. Yu, Y.; Lee, C.; Kim, J.; Hwang, S. Group-specific primer and probe sets to detect methanogenic communities using quantitative real-time polymerase chain reaction. Biotechnol Bioeng 2005, 89, 670-679. [CrossRef] [PubMed]

44. Bolyen, E.; Rideout, J.R.; Dillon, M.R.; Bokulich, N.A.; Abnet, C.C.; Al-Ghalith, G.A.; Alexander, H.; Alm, E.J.; Arumugam, M.; Asnicar, F.; et al. Reproducible, interactive, scalable and extensible microbiome data science using QIIME 2. Nat. Biotechnol. 2019, 37, 852-857. [CrossRef] [PubMed]

45. Callahan, B.J.; McMurdie, P.J.; Rosen, M.J.; Han, A.W.; Johnson, A.J.A.; Holmes, S.P. DADA2: High-resolution sample inference from Illumina amplicon data. Nat. Methods 2016, 13, 581-583. [CrossRef] [PubMed]

46. Bokulich, N.A.; Kaehler, B.D.; Rideout, J.R.; Dillon, M.; Bolyen, E.; Knight, R.; Huttley, G.A.; Caporaso, J.G. Optimizing taxonomic classification of marker-gene amplicon sequences with QIIME 2's q2-feature-classifier plugin. Microbiome 2018, 6, 1-17. [CrossRef] [PubMed]

47. DeSantis, T.Z.; Hugenholtz, P.; Larsen, N.; Rojas, M.; Brodie, E.L.; Keller, K.; Huber, T.; Dalevi, D.; Hu, P.; Andersen, G.L. Greengenes, a chimera-checked 16S rRNA gene database and workbench compatible with ARB. Appl. Environ. Microbiol. 2006, 72, 5069-5072. [CrossRef] [PubMed]

48. Gu, Z.; Eils, R.; Schlesner, M. Complex heatmaps reveal patterns and correlations in multidimensional genomic data. Bioinformatics 2016, 32, 2847-2849. [CrossRef]

49. Benjamini, Y.; Hochberg, Y. Controlling the false discovery rate: A practical and powerful approach to multiple testing. J. R. Stat. Soc. Ser. B. 1995, 57, 289-300. [CrossRef]

(C) 2020 by the authors. Licensee MDPI, Basel, Switzerland. This article is an open access article distributed under the terms and conditions of the Creative Commons Attribution (CC BY) license (http://creativecommons.org/licenses/by/4.0/). 